\title{
PENYUTRADARAAN DRAMA MUSIKAL SECANGKIR TEH KARYA ROMUALDO SITUMORANG
}

\author{
Byta Indrawati \\ Jurusan Teater, Fakultas Seni Pertunjuan, Institut Seni Indonesia Yogyakarta
}

\begin{abstract}
Abstrak: Naskah drama Secangkir Teh merupakan kisah dari seorang anak yang mempunyai impian menjadi Cinderella. Naskah drama Secangkir Teh dipilih karena belum pernah dipentaskan. Alasan pemilihan bentuk pertunjukan drama musikal dikarenakan memiliki unsur yang kompleks sebagai sebuah pertunjukan. Teori yang digunakan adalah teori penyutradaraan dari Gordon Craig. Penyutradaraan drama musikal Secangkir Teh ini menggunakan tiga metode yang meliputi bedah naskah, latihan dasar-dasar teater, dan latihan bernyanyi. Naskah Secangkir Teh karya Romualdo Situmorang kemudian telah dipentaskan pada tanggal 05 Juni 2018 di Gedung Societed Militair Taman Budaya Yogyakarta pukul 20.00 WIB dengan baik dan lancar.
\end{abstract}

Kata kunci: naskah Secangkir Teh, Impian, penyutradaraan, drama musikal.

\begin{abstract}
Secangkir Teh play script is a story of a child who has a dream of being Cinderella. Secangkir Teh play script was chosen because it had never been performed. The reason for choosing this play as a musical is because it has a complex element as a performance. The theory used is directing theory from Gordon Craig. The directing of Secangkir Teh play script uses three methods which includes play script breakdown, theater basics exercises, and singing practices. Secangkir Teh play script by Romualdo Situmorang has finally been smoothly performed on June 5, 2018 at the Societet Militair Building in Taman Budaya Yogyakarta at $20.00 \mathrm{WIB}$.
\end{abstract}

Keywords: Secangkir Teh, play script, Dream, directing, musical drama.

\section{Pendahuluan}

Naskah drama Secangkir Teh merupakan kisah dari seorang anak yang mempunyai impian menjadi Cinderella. Dongeng Cinderella karya Charles Perrault mengisahkan tentang seorang gadis yang tinggal bersama ibu tiri dan dua saudara tirinya, semenjak ibu kandungnya meninggal. Perjalanan hidup Cinderella sangat menyedihkan, Cinderella harus terus melayani ibu tiri dan dua saudara tirinya dengan sabar, karena kebaikan hati Cinderella maka datanglah sosok ibu peri yang membantu Cinderella untuk mewujudkan mimpinya beretemu sang Pangeran dan impian tersebut terwujud hingga dikisahkan Cinderella menikah dan hidup bahagia dengan sang Pangeran.

Kisah Cinderella tersebut cukup hangat dan mampu dikenang oleh banyak penggemar dongeng Charles Perrault. Cinderella dimata anak-anak sangat berkesan, karena membuat mereka melihat sosok Putri yang mereka idam-idamkan, kemudian mereka bermimpi ingin menjadi seorang Cinderella. Mimpi-mimpi tersebut tidak jarang membuat mereka terus menyakini dan menciptakan impian imajinasi untuk menjadi sosok seorang Putri.

Manusia terlahir untuk memiliki impian. Impian merupakan hasrat manusia untuk memiliki cita-cita yang mereka inginkan. Adanya impian membuat 
manusia akan bekerja keras untuk terus menggapainya. Banyak hal yang akan dilakukan oleh seorang manusia untuk menemukan impian mereka masingmasing. Keyakinan, kerja keras, serta harapan akan terus menggiring mereka menemui impiannya, namun tidak sedikit juga diantaranya yang terhalang oleh masalah-masalah yang muncul. Kodrat manusia sebagai insani itu adalah keinginan manusia untuk mengungkapkan diri, untuk menaruh minat pada realitas kehidupan, dan pada dunia khayal yang diangankan sebagai dunia nyata (Endraswara, 2016). Tidak ada keajaiban untuk menggapai impian, keajaiban akan datang ketika kita sadar dan menyakini impian tersebut tanpa ragu-ragu.

Naskah drama Secangkir Teh dipilih karena belum pernah dipentaskan. Hal ini menjadi kesempatan bagi penulis selaku sutradara untuk mementaskan naskah tersebut dalam bentuk drama musikal untuk pertama kali. Alasan pemilihan bentuk pertunjukan drama musikal dikarenakan memiliki unsur yang kompleks sebagai sebuah pertunjukan. Kompleksitas drama musikal adalah porsi bernyanyi dan berakting yang lebih besar. Akting, tarian, lagu dan penyanyi memiliki dimensi yang lebih luas dalam pertunjukan musikal karena sebuah lagu dapat menunjukan langsung karakter seseorang dan filosofi kehidupan pada penonton (Kernodle, 1978).

Penulis terinspirasi dari beberapa pertunjukan drama musikal yang populer dikalangan remaja, mulai dari film hingga pertunjukan teater. Hal tersebut terlihat dari mampunya ekstrakulikuler teater di sekolah seperti contoh Teater Puspa Negara SMAN 5 Yogyakarta berhasil mementaskan pertunjukan Drama Musikal Sampek Engtay karya N. Riantiarno produksi tahun 2017 dan Drama Musikal Opera Ular Putih karya N. Riantiarno produksi tahun 2018. Kampus seni yang juga tidak sedikit memproduksi pementasan drama musikal seperti mahasiswa Institut Seni Indonesia
Yogyakarta dan komunitas yang membuat pertunjukan drama musikal. Pertunjukan drama musikal adalah salah satu bentuk seni multidispilin yang memiliki kompleksitas tinggi dan membutuhkan kerja tim yang kuat. Fenomena ini menandakan bahwa generasi muda saat ini sangat bersemangat pada kesenian.

\section{Teori}

Naskah drama Secangkir Teh karya Romualdo Situmorang kemudian dipilih untuk dipentaskan dalam pertunjukan teater karena sampai saat ini belum ada data tentang pementasan tersebut, maka penulis selaku sutradara akan mementasakan dalam bentuk drama musikal. Keterampilan pemain di dalam pertunjukan musikal adalah pusat pertunjukan, sedangkan liberto, lirik, lagu, dan tarian semua harus dirancang agar pemain menampilkan keterampilan yang terbaik (Kernodle, 1978).

Serta beberapa dialog yang memiliki unsur nyayian pun menjadi pertimbangan sesuai dengan kebutuhan panggung yang akhirnya harus melakukan pemetaan terhadap opera, drama musik, hingga drama musikal. Opera merupakan salah satu unsur teater yang paling kuat. Opera adalah seni gabungan dari orchestra dan tanpa dialog. Opera ini lebih mengedepankan nyanyian tanpa ada dialog, hanya ekspresi dan laku tokoh yang mampu menggerakan suasana dan pergantian babak. Opera akhirnya terpecah menjadi beberapa jenis pertunjukan teater yang mengedepankan musik sebagai rangkaian cerita. Salah satunya, ialah teater musikal yang dahulunya bernama drama musik.

Drama Musik adalah jenis drama yang amat popular di Amerika, dan merupakan satu-satunya sumbangan Amerika dalam memperkaya jenis teater dunia. Drama yang diiringi musik, tari dan nyanyian ini sebelumnya sudah berakar di Eropa sejak zaman Vaudeville, Burlesque, dan Extravaganza. Pada perkembangannya menyebar ke Inggris, dari abad 17 sampai 
19. Bentuk drama ini mulai menyebar ke Amerika Serikat dan mulai popular setelah perang dunia pertama (Sumardjo, 1986). Memasuki era 20 an nama dari teater musikal berpindah lagi dan lebih popular sebagai drama musikal. Pertunjukan dalam bentuk "drama" yang mengandung unsur musik, lagu, dan tari sebenarnya tidak asing dalam dunia kesenian Indonesia, baik dalam dalam seni kontemporer maupun seni tradisional (Susantono, 2016).

Genre musik yang dipilih merupakan genre musik pop dengan beberapa alat musik yang seperti biola, flute, keyboard, bass, gitar, dan drum dalam proses drama musikal Secangkir Teh. Genre musik pop dipilih untuk mempermudah pemain dalam menghafal lagu serta genre pop yang bisa diterima oleh semua kalangan khususnya anak-anak usia remaja, karena pementasan drama musikal ini memiliki segmentasi kepada anak-anak usia remaja.

Sutradara kemudian menuju pada teori yang menjadi acuan. Teori yang digunakan merupakan teori penyutradaraan dari Gordon Craig. Teori Gordon mengacu kepada kesatuan ide antar pemain dan sutradara. Jika teater merupakan karya seni, maka karya itu harus mengekspresikan kepribadian si seniman. Akor yang dianggap baik dalam teori ini adalah aktor yang mampu mendedikasikan kerjanya terhadap ide sutradara. Kebaikan teori ini adalah hasil pementasan yang sempurna, tata tertib terjamin, teratur, dan teliti. Kelemahan atau keburukan teori ini bahwa sutradara bisa menjadi diktator, aktor dan aktris hanya menjalan alat sutradara (Dewojati, 2012).

Gordon Craig mengatakan bahwa teater bukanlah karya seni gabungan dari berbagai bentuk seni. Teater adalah seni otonom yang memiliki unsur dasar -akting, bahasa, garis, warna, dan irama- yang diolah oleh seorang seniman. Craig menyarankan sebaiknya aktor menjadi "boneka" sutradara. Posisi aktor mutlak berada di tangan sutradara, sehingga personalitasnya sebagai aktor ditentukan sutradara (Yudiariani, 2002).

\section{Metode Penciptaan}

Sutradara memiliki banyak hal yang harus dilakukan untuk mencari makna pada naskah serta cara untuk menemukan metode dalam melakukan kerja penyutradaraan. Menurut Yudiaryani (2002) pada saat sutradara sudah merasa yakin terhadap jenis naskah pilihannya, serta gaya yang ingin dipakai untuk menggambarkan plot, karakter, dan tema serta kualitas dialog, suasana dan spektakel, maka mulailah ia merencanakan semuanya dalam bentuk desain panggung. Sutradara menurut Rendra (2009) memiliki wewenang sebagai berikut:

a. Menentukan naskah yang akan dimainkan.

b. Menentukan pemilihan seluruh staf unsur tata kesenian.

c. Menentukan pemilihan pemain.

d. Jadwal latihan.

e. Tafsiran isi pertunjukan.

f. Gaya permainan para pemain.

g. Gaya ekspresi pertunjukan secara keseluruhan.

h. Memimpin latihan-latihan para pemain.

i. Mengkoordinasikan pekerjaan seluruh stafnya sehingga menjadi suatu kesatuan yang utuh.

j. Memimpin jalannya pertunjukan.

k. Mempunyai hak veto bila ada pertentangan di dalam staf unsur kesenian antar siapapun. Sebab tanpa veto ini, bila misalnya ada pertentangan, maka keutuhan ekspresi pertunjukan akan terganggu.

Penjabaran tentang metode penyutradaraan yang disampaikan oleh Rendra (2009) membuat penulis semakin jeli terhadap langkah-langkah yang akan menjadi acuan dalam proses penyutradaraan Drama Musikal Secangkir Teh. Ia harus bisa menampung dan secara kritis memilih yang baik, kemudian 
dengan kreatif menyalurkan hasil pilihannya itu ke dalam proses penciptaan bersama yang harmonis. Serta seorang sutradara adalah fihak yang paling kritis dalam menghadapi sebuah naskah. Dari naskah yang baik, sutradara akan mendapat rangsangan-rangsangan kearah terbukanya konsep-konsep teatral. Karena itu sutradara akan mengkaji naskah secermat mungkin (Anirun, 1998).

Sebagai seorang sutradara banyak hal yang harus dilakukan untuk menemukan metode penciptaan untuk proses pertunjukan agar lebih efisen. Proses menuju pertunjukan tersebut, menggunakan metode sebagai berikut:

\section{Bedah naskah}

Pembedahan terhadap naskah juga harus dilakukan agar memiliki pemahaman yang sama. Menguraikan naskah sesuai dengan peristiwa dan suasana (struktur naskah), melakukan uraian terhadap tokoh yang terdapat pada naskah, serta menguraikan isi naskah (alur cerita).

Tahap selanjutnya dalam proses ini adalah melalukan diskusi. Tahap ini merupakan pengenalan awal terhadap naskah Secangkir Teh dengan pengenalan tokoh, peristiwa, suasana, serta latar kejadian pada naskah tersebut. Metode ini dilakukan agar para pemain memiliki pemahaman yang sama, antara pemain satu dengan pemain yang lain.

\section{Latihan dasar-dasar teater}

Latihan dasar-dasar teater seperti olah tubuh, olah vokal, dan olah rasa merupakan latihan rutin yang harus terus diterapkan untuk menunjang keaktoran pada setiap pemain. Latihan tersebut dimulai pada 30 menit awal sebelum masuk pada bagian pengadeganan. Latihan dasar-dasar teater tersebut juga di imbangi dengan permainan yang memfokuskan para pemain untuk bermain keseimbangan otak kanan dan kiri.

\section{Latihan menyanyi}

Bentuk pertunjukan dari naskah drama Secangkir Teh merupakan drama musikal, maka latihan menyanyi juga terus dilakukan sebelum memulai pada proses pengadeganan. Latihan menyanyi dilakukan setelah 30 menit olah tubuh. Latihan bernyanyi adalah lanjutan dari latihan oleh tubuh. Latihan ini rutin dilakukan oleh para pemain. Diluar latihan tersebut dilakukan latihan terpisah, khusus untuk latihan bernyanyi. Hal tersebut bertujuan agar kekuatan vokal yang dimiliki oleh para pemain tidak mudah kendor dan tetap stabil.

Pelaksanaan metode diatas bertujuan untuk mencapai target yang direncanakan. Agar lebih mempermudah target serta capaian selama proses, penulis membuat tabel selama proses dimulai dari membaca, menghafal, blocking, stop and go, top tail, runthrough, latihan teknis, dress

rehearsal, hingga menuju pada pementasan. Adapun penulis mengganti skema kerja sutradara dan mengganti dengan rancangan tabel. Rancanagan tabel tersebut untuk memudahkan kerja sutradara selama proses latihan, dapat dilihat dalam Tabel. 1. 


\begin{tabular}{|l|l|l|l|l|l|l|l|l|l|l|l|l|l|l|l|l|}
\hline LATIHAN & $\begin{array}{l}\text { BULAN } \\
\text { MARET }\end{array}$ & & & $\begin{array}{l}\text { BULAN } \\
\text { APRIL }\end{array}$ & & & & $\begin{array}{c}\text { BULAN } \\
\text { MEI }\end{array}$ & & & & $\begin{array}{c}\text { BULAN } \\
\text { JUIII }\end{array}$ & & & \\
\hline Membaca & I & & & & & & & & & & & & & & & \\
\hline Menghafal & & II & III & & & & & & & & & & & & & \\
\hline Blocking & & & & IV & I & & & & & & & & & & & \\
\hline Stop and Go & & & & & & II & III & & & & & & & & & \\
\hline Top-tail & & & & & & & & IV & I & & & & & & & \\
\hline Runthrough & & & & & & & & & & II & III & & & & & \\
\hline Latihan Teknik & & & & & & & & & & & & III & & & & \\
\hline Dress Rehearsal & & & & & & & & & & & & & I & & & \\
\hline Pentas & & & & & & & & & & & & & & II & & \\
\hline
\end{tabular}

Gambar 01. Tabel Jadwal Latihan

\section{Pembahasan}

Sutradara adalah seorang pemimpin, pembimbing, pelayan, dan juru taman bagi kelompoknya (Yudiaryani, 2017). Selain itu, dia juga harus bisa mewujudkan tujuan yang hendak dicapai melalui pementasan teater yang dilakukan. Seorang sutradara juga secara langsung harus berhubungan dengan banyak pihak, yaitu seperti penulis naskah, para pemain, para pekerja (kru), biaya, sensor, dan tak jarang polisi (Riantiarno, 2001). Sutradara juga memiliki tanggung jawab yang berkaitan dengan konsep pementasan. Konsep tersebut yang nantinya akan digunakan sutradara sebagai pijakan untuk menyampaikan materi kepada para pendukung pementasan Secangkir Teh.

Bentuk

Bentuk lakon tersusun dari pengadeganan ke pengadeganan, kejadian demi kejadian, dalam tatanan yang disebut plot, teknik pengembangan struktur (Anirun, 2002). Bentuk pertunjukan yang dipilih pada naskah Secangkir Teh adalah bentuk drama musikal. Drama musikal dipilih karena tokoh dituntut untuk menyanyikan pengalaman atau perasaan mereka yang paling berkesan (Susantono, 2016), serta akan ditampilkan musik, lagu, dan juga koreografi untuk mengungkapkan suatu adegan.
Gaya

Gaya merupakan ragam penampilan sebuah pertunjukan yang berwujud dari cara penulis naskah dalam menerjemahkan cerita kehidupan di atas panggung, aturanaturan pementasan yang berlaku saat naskah ditulis, serta konsep dari sutradara untuk mementaskan naskah yang dipilih dan menegaskan makna tertentu. Gaya yang dipilih dalam mementaskan naskah Secangkir Teh adalah gaya stilisasi. Gaya stilisasi merupakan teknik pengembangan yang bertujuan memperindah gerak akting, tetapi sifat-sifat tidak mengubah sifat atau karakter tokoh.

Naskah drama Secangkir Teh merupakan kisah dari seorang anak yang mempunyai impian menjadi Cinderella. Manusia terlahir untuk memiliki impian. Impian merupakan hasrat manusia untuk memiliki cita-cita yang mereka inginkan. Adanya impian membuat manusia akan bekerja keras untuk terus menggapainya. Banyak hal yang akan dilakukan oleh seorang manusia untuk menemukan impian mereka masing-masing. Keyakinan, kerja keras, serta harapan akan terus menggiring mereka menemui impiannya, namun tidak sedikit juga diantaranya yang terhalang oleh masalahmasalah yang muncul. Kodrat manusia sebagai insani itu adalah keinginan manusia untuk mengungkapkan diri, untuk menaruh minat pada realitas kehidupan, 
dan pada dunia khayal yang diangankan sebagai dunia nyata (Endraswara, 2016). Tidak ada keajaiban untuk menggapai impian, keajaiban akan datang ketika kita sadar dan menyakini impian tersebut tanpa ragu-ragu.

Naskah drama Secangkir Teh dipilih karena belum pernah dipentaskan. Hal ini menjadi kesempatan bagi penulis selaku sutradara untuk mementaskan naskah tersebut dalam bentuk drama musikal untuk pertama kali. Alasan pemilihan bentuk pertunjukan drama musikal dikarenakan memiliki unsur yang kompleks sebagai sebuah pertunjukan. Kompleksitas drama musikal adalah porsi bernyanyi dan berakting yang lebih besar. Akting, tarian, lagu dan penyanyi memiliki dimensi yang lebih luas dalam pertunjukan musikal karena sebuah lagu dapat menunjukan langsung karakter seseorang dan filosofi kehidupan pada penonton (Kernodle, 1978).

\section{Proses Penyutradaraan}

Berikut proses penyutradaraan yang dilakukan penulis selama perjalanan proses kreatif menuju pementasan Drama Musikal Secangkir Teh karya Romualdo Situmorang:

Pemilihan Pemain

Pemilihan para pemain dilakukan oleh sutradara dengan sistem casting atau menyeleksi para pemain, casting adalah proses menentukan pemain berdasarkan analisis teks drama untuk pertunjukan dengan mencoba tahapan menurut Harymawan (1988) adalah sebagai berikut:

a. Casting by ability: casting yang didasarkan pada kecakapan, pemain yang terpandai dan terbaik dipilih untuk peran penting atau utama atau sukar.

b. Casting to type: pemilihan berdasarkan kecocokan fisik si pemain.

c. Antitype to type: pemilihan yang bertentangan dengan watak atau fisik si pemain, menentang keumuman jenis perwatakan manusia secara konvensional, sering disebut educational casting.

d. Casting to emotional temperament: memilih seseorang berdasarkan hasil observasi hidup pribadinya, karena mempunyai banyak kesamaan atau kecocokan dengan peran yang akan dipegangnya (kesamaan emosi, temperamen, dan lain-lain).

e. Therapeutic-casting: mentukan seorang pelaku yang bertentangan dengan watak aslinya dengan maksud menyembuhkan atau mengurangi ketakseimbangan jiwanya.

Berikut merupakan daftar pemain pementasan Secangkir Teh:
a. Putri
: Yunita Nursafitri
b. Cinderella
: Elnani Yuliana
c. Ketua Peri
Khoriul Anwar
d. Peri 1
: Jody Dewatama
e. Peri 2
: Binti Wasingatul
f. Peri 3
: Bagus Ariyanto
g. Mamah
: Rahayu
h. Ratu Mimpi : Viola Alexandra
i. Ratu Peri : Shinta Kusuma
j. Teman Putri : Ilham Hadi
k. Miss Bahagia : Nuril Azizah

Pemain yang sudah terpilih dan mendapatkan peran kemudian harus berlatih secara ekstra untuk tahap berikutnya, yaitu menari dan bernyanyi. Tahap ini dilakukan setiap pertemuan dalam latihan serta waktu tambahan lain di luar jam latihan dengan jadwal yang telah disepakati.

\section{Pemilihan Tim Kreatif}

Pemilihan tim kreatif terbagi menjadi dua bagian, yaitu tim kreatif bidang artistik dan tim kreatif bidang manajemen produksi. Kemudian sutradara dan seluruh tim kreatif bekerja secara kolektif untuk mewujudkan konsep serta gagasan yang telah disepakati. Berikut adalah susunan tim kreatif atau 
keproduksian dari pementasan Secangkir Teh:
a. Produksi
: HMJ Teater
b. Pimpinan Produksi : Nur Alfyah
c. Stage Manager : Mega Dwi
d. Penata Artistik: Anugrah Bangun
e. Penata Cahaya : Ibnu Shohib
f. Penata Busana : Binti Dewi
g. Penata Rias :Juraiz Taftazani
h. Penata Musik:Bintang Chistian

\section{Bedah Naskah dan Diskusi}

Pembedahan terhadap naskah juga harus dilakukan agar memiliki pemahaman yang sama. Menguraikan naskah sesuai dengan peristiwa dan suasana (struktur naskah), melakukan uraian terhadap tokoh yang terdapat pada naskah, serta menguraikan isi naskah (alur cerita). Tahap selanjutnya dalam proses ini adalah melalukan diskusi. Tahap ini merupakan pengenalan awal terhadap naskah Secangkir Teh dengan pengenalan tokoh, peristiwa, suasana, serta latar kejadian pada naskah tersebut. Metode ini dilakukan agar para pemain memiliki pemahaman yang sama, antara pemain satu dengan pemain yang lain.

\section{Latihan Bernyanyi}

Bentuk pertunjukan dari naskah drama Secangkir Teh merupakan drama musikal, maka latihan menyanyi juga terus dilakukan sebelum memulai pada proses pengadeganan. Latihan menyanyi dilakukan setelah 30 menit olah tubuh. Latihan bernyanyi adalah lanjutan dari latihan oleh tubuh. Latihan ini rutin dilakukan oleh para pemain. Diluar latihan tersebut dilakukan latihan terpisah, khusus untuk latihan bernyanyi. Hal tersebut bertujuan agar kekuatan vokal yang dimiliki oleh para pemain tidak mudah kendor dan tetap stabil.

Latihan Menari

Latihan menari menjadi penting, agar para pemain dapat mencapai gerakgerak yang mendukung suasana dari lagu yang dinyanyikan. Latihan tari yang dilakukan merupakan latihan tari kontemporer atau pengembangan dari gerakan-gerakan yang mendukung suasana pada beberapa adegan. Adegan awal dibuka dengan tarian serta permainan anak yang membantu menciptakan suasana pagi setelah anak-anak bangun tidur, adegan kedua tarian Para Peri mencari Cinderella, pada adegan ini Para Peri membuat koreografi yang mengambarkan mereka sedang mencari Cinderella kemudian kelelahan. Adegan berikutnya TemanTeman dunia mimpi Putri datang dan menari untuk menciptakan suasana yang gembira yang bersemangat. Adegan ketiga, koreografi untuk Para Peri yang menari dan menyanjung Putri seperti Cinderella, kemudian adegan selanjutnya datang Teman-Teman dunia mimpi Putri yang datang untuk menari dan menyanyi selamat ulang tahun dan menghibur Putri. Latihan tersebut juga mengandung unsurunsur pertunjukan teater, yaitu levelitas, komposisi, dan bloking.

\section{Latihan Terpisah}

Latihan terpisah dilakukan karena beberapa pemain yang sulit untuk latihan bersama. Latihan ini juga menjadi bagian dari latihan keseluruhan, untuk latihan terpisah penulis mengadakan latihan khusus untuk bernyanyi dan menari. Metode latihan terpisah ini dinilai lebih efektif, karena pada jam latihan penulis tetap bisa menggarap adegan dengan tambahan hasil yang sudah didapat dari latihan terpisah. Latihan menyanyi diadakan padea hari Jumat dan Sabtu pukul 20.00 malam serta latihan menari diadakan pada hari Selasa dan Minggu pukul 20.00 malam.

\section{Latihan Rutin}

Latihan rutin merupakan latihan dari jadwal yang sudah disepakati, hari Senin, Selasa, dan Kamis pukul 19.00 malam, kemudian menggabungkan hasil dari latihan terpisah, yaitu latihan bernyanyi, serta latihan tari. Latihan rutin ini dilakukan untuk mewujudkan keseimbangan pementasan. Sutradara 
kemudian merajut dramatik antara adegan dengan tempo permainan. Proses latihan juga menggarap blocking pemain, blocking merupakan teknik pengaturan langkahlangkah para seniman dipanggung ketika membawakan sebuah cerita drama (Anirun, 2002). Latihan rutin ini dibagi dalam beberapa tahapan latihan diantaranya:

\section{Latihan Dialog (Reading)}

Latihan dialog atau reading merupakan latihan para pemain untuk membangun chemistry sebagai metode menghafal teks. Latihan dialaog atau reading ini dimulai saat awal proses berlangsung. Seluruh pemain akan membaca naskah secara bergantian sesuai dialog serta peran yang sudah ditetapkan. Tidak sedikit pemain yang merasa binging dengan jalan cerita maupun perpindahan adegan yang terkesan buru-buru, sutradara kemudian menjelaskan maksud dialog yang tidak dimengerti serta menjelaskan maksud peristiwa pada setiap adegan. Pemain yang paham pun kemudian membantu memberikan pengertian kepada pemain yang lain. Pada proses membaca tidak hanya para pemain dan sutradara saja yang ikut berdiskusi melainkan para pemusik juga ikut untuk mengerti maksud dari isi naskah tersebut.

\section{Latihan Blocking}

Latihan blocking merupakan pelatihan yang menggabungkan dialog serta pergerakan para pemain diatas panggung. Pada latihan blocking para pemain mencoba untuk mengeksplor gerak, maka sutradara akan melihan bagaimana para pemain mencoba untuk memberi penawaran disetiap adegan kemudian sutradara mengunci atau sepakan dengan penawaran yang dilakukan pada adegan, maka blocking tersebut yang akan dilatihkan dan diberi tekanan emosi pada latihan run selanjutnya. Beberapa pemain juga ada yang terlihat pasif dan menunggu arahan sutradara untuk bergerak makan akan ada tensi yang cukup keras untuk para pemain yang dinilai malas dalam proses latihan, maka sutradara terkadang harus mencoba untuk menjelaskan peristiwa yang sedang terjadi.

\section{Cut to cut dan Runthrough}

Latihan cut to cut merupakan cara untuk memperbaiki garis dan permainan atau acting. Latihan cut to cut tidak sedikit para pemain yang terkadang lupa dengan kesepakan yang dibuat dengan pemain lain maupun kepada sutradara, maka pada latihan ini untuk membiasakan dialog, gerak, gesture, nyanyian, serta tarian yang sudah dilakukan sebelumnya. Latihan runthrough adalah latihan uji coba pengadeganan dari awal adegan sampai akhir adegan. Latihan cut to cut dan runthrough dilakukan agar setiap adegan dan acting yang dilakukan para pemain dapat diperbaiki kemudian diuji cobakan sehingga dapat di evaluasi pada akhir runthrough.

\section{Presentasi}

Presentasi merupakan hasil dari latihan yang kemudian dipresentasikan kepada dosen pembimbing dan temanteman. Presentasi dilakukan agar banyak masukan dan saran yang dapat membantu proses latihan serta pertunjukan penyutradaraan drama musikal Secangkir Teh. Banyak masukan yang diberikan oleh dosen pembimbing kepada sutradara, namun tidak semua masukan tersebut dapat diaplikasikan karena terkendala oleh kemampuan pemain seperti akrobatik dan bernyanyi, namun sutradara dapat menyiasati dan mengganti dengan tarian dan mengubah nyanyian panjang menjadi dialog.

\section{Evaluasi}

Tahap evaluasi dilakukan setelah selesai latihan, sutradara, para pemain dan seluruh tim kreatif berhak memberikan evaluasi untuk menilai capaian latihan. Evaluasi dilakukan untuk menelaah kesalahan, mencari solusi, serta mengatur hasil kinerja. Hasil evaluasi yang rutin 
disampaikan setiap selesai latihan akan menjadi acuan proses latihan selanjutnya. Hasil evaluasi juga menjadi arsip dan dokumentasi tertulis dalam proses pementasan Secangkir Teh.

\section{Gladi Kotor}

Galdi kotor dilakukan sebelum menuju ke pertunjukan, hal ini dilakukan untuk mencoba untuk berlatih lebih maksimal dengan semua pendukung yang terlibat. Koreksi yang diberikan oleh sutradara biasanya lebih pada detail dari adegan atau cara bermain aktor/aktris. Gladi kotor tidak dapat berjalan dengan maksimal karena para pemain sedang hilir mudik dengan ujian akhir semester serta proses tugas akhir yang lain dan terkendala tempat latihan, namun permasalahan tersebut dapat terkondisikan tetapi kurang maksimal. Jalan keluar yang dipilih kemudian tetap melaksanakan gladi kotor dengan sisa waktu yang ada serta mencoba dengan maksimal.

\section{Simpulan}

Sutradara memiliki tanggung jawab untuk menyatukan seluruh kekuatan dari berbagai elemn teater. Sebagai seorang sutradara, ia harus mempunyai argumen atau alasan yang kuat, dan jelas dalam memilih naskah tertentu. Selain itu, sutradara harus bisa mewujudkan tujuan yang ingin dicapai melalui pementasan teater. Hal-hal penting yang harus dilakukan adalah menjalani proses sejak perencanaan, pelatihan hingga pementasan, agar dapat menentukan hasil akhir yang maksimal.

Selama perjalanan tersebut penulis mendapat banyak dukungan serta bantuan dari banyak pihak, terutama dari tim kreatif lain yang tidak tergabung dalam struktur keproduksian. Selama proses kreatif berlangsung dapat disimpulkan bahwa mentukan pesan apa yang ingin disampaikan oleh kreator pada penonton merupakan hal yang sangat penting. Naskah Secangkir Teh karya Romualdo Situmorang diketik ulang oleh Byta
Indrawati dan dipentaskan pada tanggal 05 Juni 2018 di Gedung Societed Militair Taman Budaya Yogyakarta pukul 20.00 WIB dengan harapan bahwa seni pertunjukan, disangga oleh 4 pilar yaitu, pengkarya/seniman, produksi, penonton dan kritikus. Pementasan Secangkir Teh memberikan bagian dari 4 pilar tersebut kepada penonton dan inilah hasil dari proses penciptaan.

\section{Daftar Pustaka}

Anirun, S. (2002). Menjadi Sutradara, Bandung: STSI Press.

Endraswara, S. (2016). Metodologi Penelitian Posmodernisme Sastra

Yogyakarta: Center of Academic Publishing Service.

Dewojati, C. (2012). Drama, Sejarah, Teori, dan Penerapannya. Yogyakarta: Javakarsa Media.

Harymawan, R.M.A. (1988). Dramaturgi. Bandung: Rosda Karya.

Kernodle, G. (1978). Invitation to The Theatre. United States of America (USA): Harcourt Brace Jovanovich.

Rendra. W.S. (2009). Seni Drama Untuk Remaja, Jakarta: Burungmerak Press.

Riantiarno, N. (2001). Kitab Teater, Jakarta: Gramedia Widiarsana Indonesia.

Sumardjo, J. (1986). Ikhtisar Sejarah Teater Barat, Bandung: Angkasa.

Susantono, N. P. (2016). Produksi Drama Musikal-Dari Ide ke Panggung, Jakarta: Gramedia.

Yudiariyani. (2002). Panggung Teater Dunia, Yogyakarta: Pustaka Gondho Suli.

Yudiariyani. (2017). Karya Cipta Seni Pertunjukan. Yogyakarta: JB Publisher. 